\title{
DESAIN APLIKASI E-COMMERCE SEBAGAI MEDIA PROMOSI PRODUK BUMBU MASAKAN KELOMPOK TANI MUTIARA INDAH
}

\author{
Budi Rahmadya ${ }^{1}$, Ahmad Syafruddin Indrapriyatna ${ }^{2}$, Khandra Fahmy ${ }^{3}$, Dodon Yendri ${ }^{4}$, \\ Derisma $^{5}$, dan Nefy Puteri Novani ${ }^{6 *)}$ \\ ${ }^{1,4,5,6}$ Fakultas Teknologi Informasi, Universitas Andalas \\ ${ }^{2}$ Fakultas Teknik, Universitas Andalas \\ ${ }^{3}$ Fakultas Teknologi Pertanian, Universitas Andalas \\ *) Email: nefyputeri@fti.unand.ac.id
}

\begin{abstract}
ABSTRAK
Usaha kelompok Tani Mutiara Indah Kabupaten Tanah Datar dalam memproduksi bumbu masakan merupakan salah satu usaha kecil dan menengah (UKM) unggulan yang ada di kabupaten Tanah Datar. Permasalahan yang ada pada UKM ini adalah masalah pemasaran produk dan sistem produksi yang masih bersifat pesanan. Salah satu kelemahan sistem pesanan ini adalah waktu perputaran uang yang cukup lama. Pemanfaatan e-commerce merupakan salah satu solusi untuk mengatasi kendala pemasaran dan sistem penjualan pada UKM ini. Dengan memanfaatkan internet melalui aplikasi e-commerce membuka peluang bagi UKM Kelompok Tani Mutiara Indah ini untuk memasarkan produknya dan menumbuhkan akses ke jaringan pasar yang lebih luas. Selain itu, transaksi di e-commerce dapat dilakukan dengan tunai tergantung kemampun penjual dalam mendesain sistem penjualan. Hal ini memungkinkan perputaran kas dapat lebih cepat dan memberikan keuntungan yang juga lebih besar. Telah dilaksanakan pelaksanaan kegiatan ini untuk membekali anggota Kelompok Tani Mutiara Indah dengan pengetahuan tentang penggunaan aplikasi e-commerce yang dapat mereka manfaatkan dalam memasarkan produk bumbu secara lebih luas dan memperluas jaringan penjualannya produknya.
\end{abstract}

Kata Kunci : kelompok tani, usaha kecil dan menengah, e-commerce, media promosi

\section{E-commerce Application Design as a Promotion Media For Bumb Products Cuisine of Mutiara Indah Group Farming}

\begin{abstract}
The business of the Mutiara Indah Farmers in Tanah Datar District in the food spice business is one of the leading small and medium enterprises (SMEs) in Tanah Datar district. The problems that exist in this SMEs are: Products and production that are still in order. One of the errors in this order system is the long turn-around time of money. The use of e-commerce is one of the solutions to the process and sales process for this SMEs. Using the internet through e-commerce applications opens opportunities for SMEs Mutiara Indah Farmers Group to market their products and grow access to a wider market network. In addition, transactions on e-commerce can be done with payments depending on the seller in designing the sales system. This allows cash turnover to be faster and provide greater benefits. This service activity has been carried out to equip members of the Mutiara Indah Farmers Group with knowledge about the use of e-commerce applications that they can use in marketing wider products and expanding their product sales network.
\end{abstract}

Keywords : farmer groups, small and medium enterprises, e-commerce, media promotion 


\section{PENDAHULUAN}

Usaha kecil dan menengah (UKM) merupakan salah satu satu pilar ekonomi Indonesia. Sektor ini memberikan kontribusi terhadap APBD sebesar 58,92 persen dan kontribusi dalam penyerapan tenaga kerja 97,30 persen (merdeka.com, 2014). Kontribusi ini tentu cukup besar bagi pendapatan masyarakat maupun penyerapan tenaga kerja. Dengan peran yang cukup besar ini diharapkan UKM juga mampu bersaing dalam menghadapi pasar bebas.

Berbagai persoalan selalu dihadapi oleh usaha kecil dalam pengembangan usahanya dan membangun kekuatan bersaing. Persoalan itu meliputi kendala modal, akses pasar yang terbatas, kualitas sumber daya manusia yang mengelola termasuk juga kemampuan pengelolaan dan pelaporan keuangan. Untuk itu usaha kecil dan menengah (UKM) harus senantiasa didorong untuk mampu mengatasi berbagai kelemahan yang dimiliki. Hal ini bertujuan agar UKM dapat mengatasi berbagai kelemahan dan mampu bersaing serta tidak jatuh tertindas oleh kompetitornya.

Kemajuan teknologi yang sangat cepat serta perkembangan globalisasi menuntut masyarakat untuk mempersiapkan diri agar menjadi bagian dari perkembangan tersebut. Kemajuan teknologi telah merambah berbagai bidang termasuk bidang ekonomi. Internet economy mendorong globalisasi dan networking dalam dunia usaha. Kondisi ini menjadikan pasar dan perdagangan makin terbuka tanpa batas, serta peluang yang setara bagi pelaku-pelaku bisnis, tidak mengenal apakah berasal dari perusahaan besar, menengah, ataupun kecil, siapa yang cepat akan menang.

Di era globalisasi, informasi bergerak sangat cepat dan menjadi pelaku bisnis untuk memenangkan persaingan. Internet melalui e-commerce membuka peluang bagi usaha kecil dan menengah (UKM) untuk memasarkan dan menumbuhkan jaringan usaha di seluruh belahan dunia usaha. Untuk itu pelaku Usaha Kecil dan Menengah (UKM) dituntut menjadi bagian dari komunitas global dengan pemanfaatan teknologi informasi melalui e-commerce, jika mereka tidak mengikuti perkembangan teknologi informasi akan tertinggal jauh dan kalah dalam persaingan. E-commerce merupakan salah satu cara yang dapat dimanfaatkan oleh pelaku usaha Kecil dan Menengah (UKM) untuk kemudahan memasarkan produknya dalam wilayah yang lebih luas dan membuka kesempatan pasar yang lebih efisien. Hal ini menjadi peluang yang sangat strategis bagi UKM.

Usaha kelompok Tani Mutiara Indah dalam memproduksi bumbu masakan merupakan salah satu usaha unggulan yang ada di kabupaten Tanah Datar. Usaha ini merupakan usaha yang dilakukan sejak lama sejalan dengan perkembangan zaman dan kebutuhan akan bumbu masakan. Permasalahan yang umum terjadi di UKM ini adalah masalah pemasaran produk. Sistem produksi yang dilakukan bersifat pesanan. Jika mereka mampu mencari pedagang pengumpul dan relasi, mereka dapat memperoleh pesanan yang cukup banyak. Jika tidak, kegiatan produksi bisa saja terhenti saat tidak ada pesanan. Salah satu kelemahan sistem pesanan ini adalah waktu perputaran uang yang cukup lama. Para pemesan baru akan membayar pesanan mereka beberapa minggu bahkan beberapa bulan kemudian. Akibatnya, modal kerja mereka tertahan di tangan pembeli dalam bentuk piutang. Padahal sebagai UKM para pengusaha bumbu ini juga dihadapkan pada masalah ketersediaan modal usaha. Persoalan semacam ini rata-rata dihadapi oleh semua pengusaha UKM. 
Pemanfaatan e-commerce merupakan salah satu solusi untuk mengatasi kendala pemasaran UKM ini. Melalui e-commerce, pengusaha bumbu masakan dapat mengakses pasar yang lebih luas. Apalagi prospek bumbu masakan asal Propinsi Sumatera Barat khususnya Kabupaten Tanah Datar cukup bagus. Selain itu, transaksi di e-commerce dapat dilakukan dengan tunai tergantung kemampun penjual dalam mendesain sistem penjualan. Hal ini memungkinkan perputaran kas yang lebih cepat dan memberikan keuntungan yang juga lebih besar.

Pemanfaatan e-commerce oleh pengusaha bumbu masakan memberikan peluang juga tantangan dan kelemahan. Salah satu kelemahan utama adalah kurangnya kemampuan dalam mengaplikasikan e-commerce. Beberapa pengusaha UKM di Kabupaten Tanah Datar selama ini telah mulai mencoba memasarkan produknya secara online melalui media sosial seperti facebook, bbm, dan lainnya. Namun hal ini belum memberikan hasil yang optimal. Beberapa kelemahan yang terlihat misalnya pemasaran melalui facebook masih tercampur dengan aktivitas sosial media. Akhirnya promosi mereka kurang intensif. Kedua, produk yang ditampilkan belum dikemas secara menarik. Foto produk kurang bagus dan jelas. Belum ada penjelasan yang detail dan kurangnya informasi tentang cara pemesanan maupun pembayaran.

Berdasarkan paparan di atas, maka tim tertarik untuk menyelenggarakan pelatihan dengan judul Desain Aplikasi E-Commerce Sebagai Media Promosi Produk Bumbu Masakan Kelompok Tani Mutiara Indah. Pelatihan ini akan diberikan kepada anggota Kelompok Tani Mutiara Indah yang potensial untuk menyelenggarakan e-commerce. Peserta nanti akan dipilih sesuai dengan kriteria yang ditetapkan yaitu melek internet dan memiliki gadget yang dapat dimanfaatkan untuk mengakses internet.

\section{METODE}

\section{A. Rencana Kegiatan}

Kegiatan pelatihan yang diberikan bagi Kelompok Tani Mutiara Indah di Cubadak Limo Kaum Kabupaten Tanah Datar direncanakan dalam uraian tahapan kegiatan sebagai berikut:

1. Persiapan

Melakukan pertemuan awal dengan koordinator Kelompok Tani Mutiara Indah untuk menentukan dan menyepakati jadwal dan tempat pelaksanaan kegiatan. Pada kegiatan persiapan juga akan dilakukan pendataan dan penetapan peserta pelatihan. Salah satu komitmen yang perlu ditekankan adalah kesediaan peserta mengikuti setiap rangkaian acara dari awal sampai selesai.

2. Kegiatan inti

Pertemuan ini direncanakan selama dua hari dengan agenda sebagai berikut:

a) Pada pertemuan pertama dilakukan pemaparan materi diselingi tanya jawab dan diskusi.

b) Pada pertemuan berikutnya dilakukan praktek e-commerce dengan memanfaatkan media sosial yang telah dimiliki oleh Kelompok Tani Mutiara Indah semisal facebook atau bbm.

3. Tahap akhir

Setelah pelaksanaan kegiatan workshop, maka dilanjutkan dengan evaluasi dan 
refleksi program yang telah dilaksanakan.

\section{B. Metode Pendekatan yang Ditawarkan}

Dalam menyelesaikan masalah, tantangan, atau persoalan yang dihadapi oleh usaha Kelompok Tani Tani Mutiara Indah di Kabupaten Tanah Datar, metode pendekatan yang dilaksanan diuraikan dalam beberapa kegiatan berikut;

1. Informasi dan diskusi

Metode ini digunakan untuk memperkenalkan materi tentang e-commerce kepada kelompok tani. Pemberian informasi dan materi ini diselingi dengan diskusi dan tanya jawab untuk mendapatkan respon dan umpan balik dari peserta kelompok tani tentang materi yang disampaikan.

2. Diskusi kelompok dan latihan terbimbing

Setelah diberikan pemaparan materi, peserta dibagi dalam beberapa kelompok beranggotakan 4-5 orang. Masing-masing kelompok ditugasi untuk membuka situs toko online yang sudah ada dan berdiskusi tentang berbagai hal yang dapat mereka amati pada situs tersebut. Dalam kelompok ini juga difasillitasi untuk demonstrasi atau percontohan untuk realisasi desain aplikasi e-commerce yang akan dikembangkan.

3. Evaluasi

Pada tahap ini peserta dan fasilitator melakukan refleksi dan evaluasi terhadap pelatihan yang telah dilakukan agar dapat menjadi bahan masukan untuk desain aplikasi e-commerce yang dikembangkan untuk usaha kelompok tani ini.

\section{Partisipasi Mitra dalam Pelaksanaan Kegiatan}

Kelompok Tani Mutiara Indah di Cubadak Limo Kaum Kabupaten Tanah Datar dalam kegiatan ini berpartisipasi aktif dalam kegiatan pelatihan dengan menjadi audience serta ikut langsung dalam seluruh rangkaian kegiatan pelatihan. Mitra juga berpartisipasi dalam menyediakan tempat pelatihan dan membantu kegiatan administratif seperti membagi undangan peserta dan tamu undangan.

\section{Rancangan Evaluasi}

Keberhasilan kegiatan pelatihan ini nantinya dapat terlihat dari keaktifan peserta dalam mengikuti pelatihan. Antusiasme dalam kegiatan dan juga feed back yang muncul dari peserta selama kegiatan pelatihan. Kegiatan evaluasi diperlukan untuk melihat sejauhmana pemahaman serta keterampilan Kelompok Tani Mutiara Indah di Cubadak Limo Kaum Kab. Tanah Datar dalam menggunakan e-commerce. Evaluasi atas kegiatan ini akan dilakukan dalam bentuk angket dan diskusi dengan peserta tentang efektifitas kegiatan ini bagi pengembangan usaha mereka.

\section{E. Jadwal Pelaksanaan Kegiatan}

Pelaksanaan kegiatan ini dilakukan berdasarkan rancangan pada 
Tabel 1. Jadwal Pelaksanaan Kegiatan

\begin{tabular}{|c|c|c|c|c|c|c|c|c|c|}
\hline \multirow{2}{*}{ No } & \multirow{2}{*}{ Kegiatan } & \multicolumn{8}{|c|}{ Bulan } \\
\hline & & 1 & 2 & 3 & 4 & 5 & 6 & 7 & 8 \\
\hline 1. & Persiapan & $\mathrm{v}$ & $\mathrm{V}$ & & & & & & \\
\hline 2. & Penyediaan alat/bahan & & & $\mathrm{v}$ & & & & & \\
\hline 3. & Kegiatan Penyuluhan & & & & $\mathrm{v}$ & & & & \\
\hline 4. & Evaluasi & & & & & $\mathrm{v}$ & & & \\
\hline 5. & Laporan & & & & & & $\mathrm{V}$ & $\mathrm{v}$ & $\mathrm{V}$ \\
\hline
\end{tabular}

\section{HASIL DAN PEMBAHASAN}

\section{A. Desain E-Commerce}

Dalam pembuatan desain aplikasi e-commerce ini mengacu kepada diagram alur seperti pada Gambar 1.

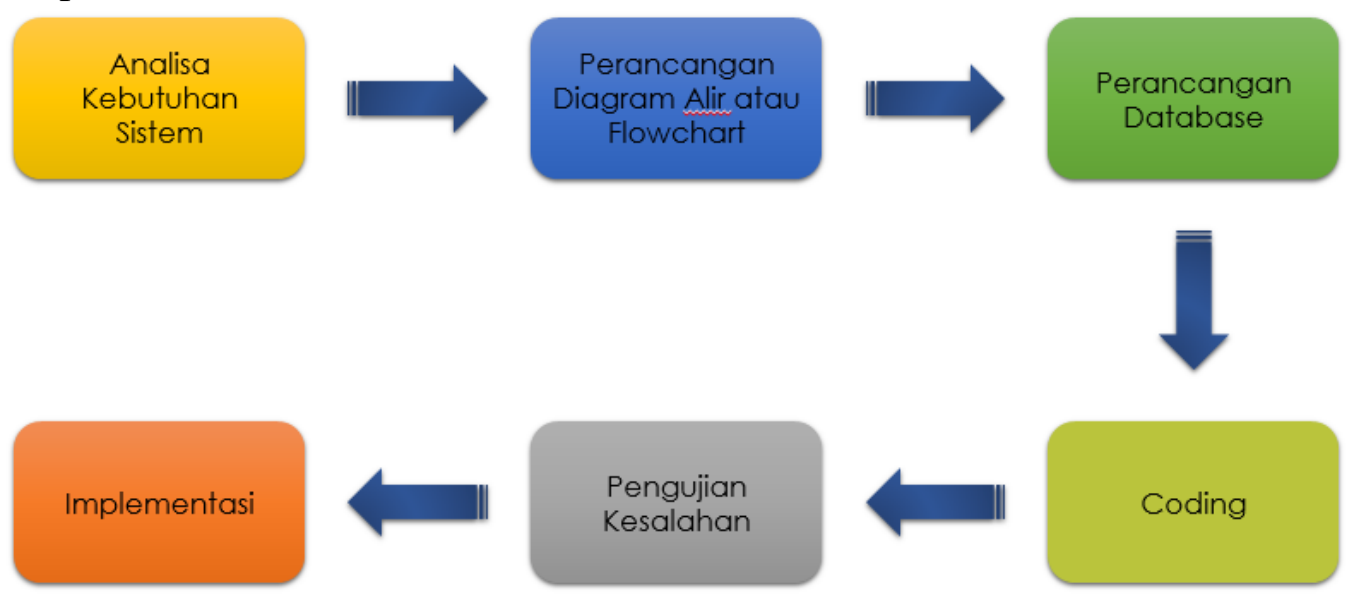

Gambar 1. Alur Desain E-Commerce

1) Analisa Kebutuhan Sistem

Pada tahap ini dilakukan survey dan wawancara dengan pengelola usaha kelompok tani dan didapatkan kesimpulan dari e-commerce yang dibutuhkan dengan mengacu kepada dua poin dibawah ini.

1. Website atau aplikasi yang dibuat berfungsi untuk pemasaran dan penjualan dari produk.

2. Admin dapat melakukan update data baru dan penghapusan data pada website.

2) Perancangan Diagram Alir

Setelah didapatkan kebutuhan dari sistem aplikasi, selanjutnya adalah melakukan perancangan sistem aplikasi dengan pembuatan use case diagram dan data flow diagram. Use case diagram memperlihatkan apa saja yang dapat dilakukan dan apa saya yang dapat terjadi pada masing-masing actor. 


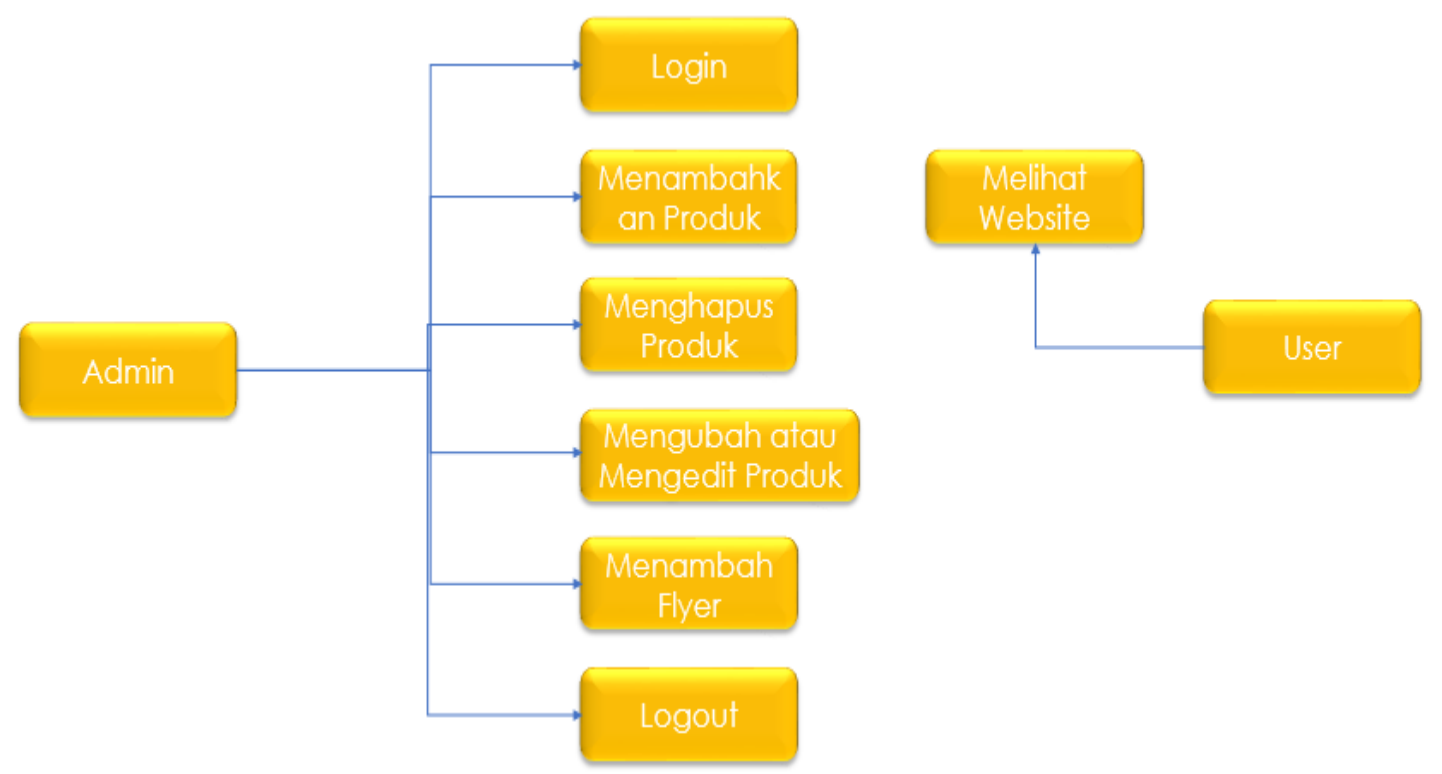

Gambar 2. Use case diagram

3) Perancangan Database

Pada tahap ini, perancangan database berfungsi untuk pengolahan informasi yang tersimpan di server secara sistematis sehingga data mudah untuk di akses oleh user.

4) Coding

Dalam pemrograman aplikasi ini menggunakan beberapa Bahasa yaitu :

a. Bahasa Markup HTML untuk pembuatan struktur aplikasi.

b. Bahasa pemrograman PHP untuk pembuatan logika aplikasi dan pengaksesan database.

c. Bahasa SQL untuk pengolahan database.

d. CSS untuk mendesain tampilan dari aplikasi agar lebih menarik.

Dan aplikasi yang digunakan dalam memprogram aplikasi yaitu :

a. Visual Studio Code, yang berfungsi sebagai text editor selama memprogram aplikasi.

b. XAMPP, yang berfungsi sebagai penyedia server local dan database MySQL yang digunakan oleh aplikasi.

5) Pengujian Kesalahan

Pengujian kesalahan atau error testing bertujuan untuk menguji apakah masih ada terdapat kesalahan pada implementasi aplikasi. Jika terjadi kesalahan maka akan dilakukan perbaikan. Setelah aplikasi selesai diuji secara keseluruhan dan tidak ada lagi ditemukan kesalahan, maka aplikasi ini akan diperlihatkan kepada user.

\section{B. Implementasi E-Commerce}

Pada tahapan ini adalah implementasi dari semua aplikasi yang telah dibuat. Implementasi dilakukan dimana domain dari e-commerce telah dionlinekan.

1) Tampilan E-Commerce

Nama domain dari e-commerce ini adalah www.bumbuminangunieque.com. Nama ini dipilih atas dasar persetujuan dari semua anggota kelompok tani yang diketuai 
oleh ibu Camelia C. Dasar dari nama ini adalah terjadinya proses pengolahan hasil pertanian lokal yang ada, menjadi bumbu masakan minang dan cemilan minang lainya. Adapun tampilan dari beranda e-commerce seperti yang terlihat pada Gambar 3.
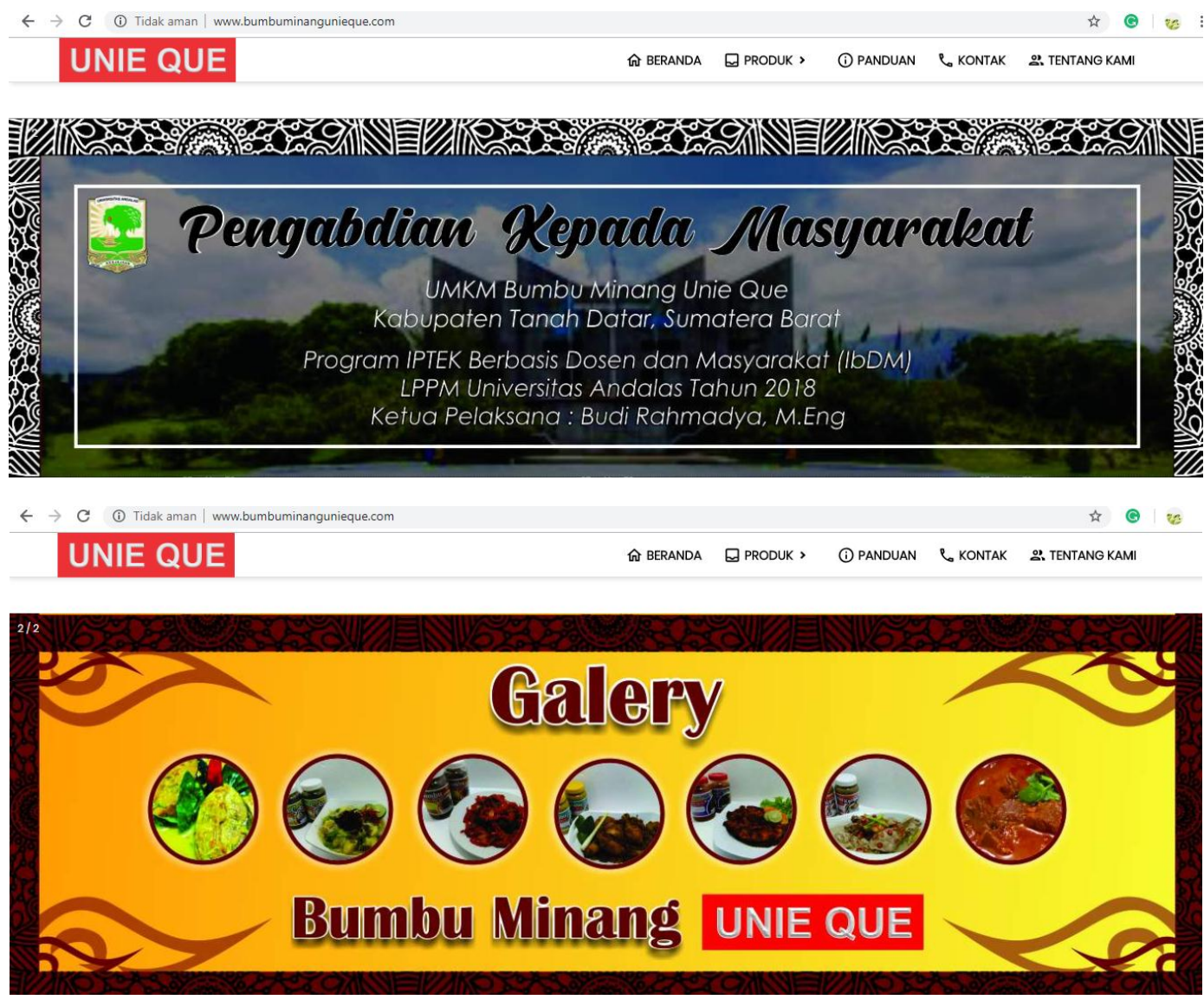

Gambar 3. Beranda e-commerce www.bumbuminangunieque.com

Dalam tampilan e-commerce ini terdiri dari beberapa menu tab yang dibuat, yang berfungsi untuk pembagian dari menu yang di sajikan pada website. Adapun menu tab tersebut adalah Produk, Panduan, Kontak dan Tentang Kami.

2) Tab Produk

Berisikan informasi tentang jenis produk yang ada di website. Produk yang di jual tidak hanya berupa bumbu minang seperti bumbu sampadeh, dendeng, rending, tetapi juga makanan minang yang lainya yang siap disajikan seperti kipang kacang, kerupuk ikan, kacang tojin dan lain-lain. 


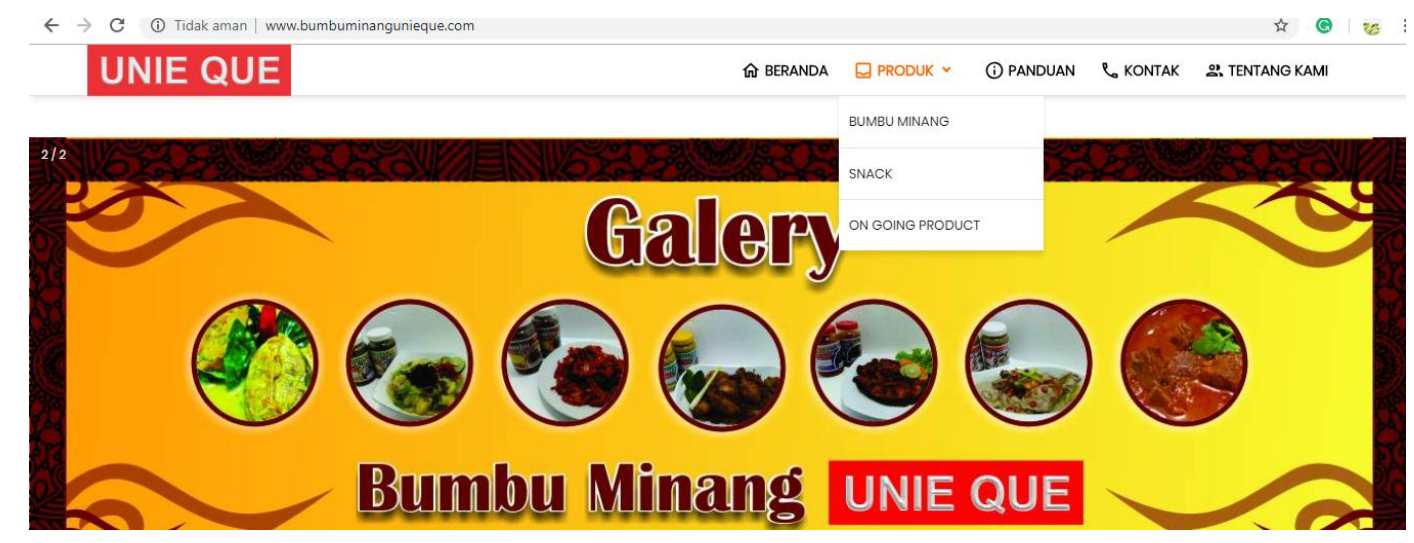

Gambar 3. Tampilan Tab produk pada e-commerce www.bumbuminangunieque.com

3) Tab panduan

Berisikan informasi mengenai cara pemesanan produk.

4) Tab Kontak

Berisikan informasi kontak gallery bumbu minang unieque.

5) Tab Tentang Kami

Berisikan informasi tentang sejarah lahirnya usaha bumbu minang unieque.

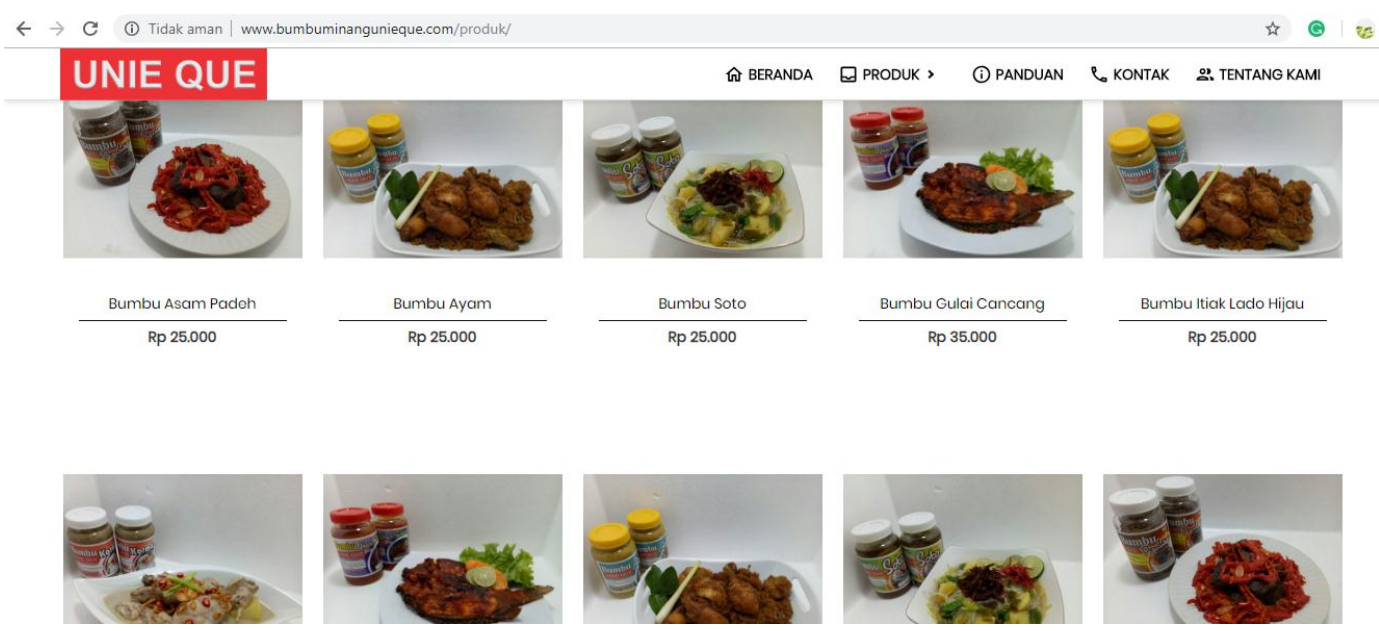

Gambar 4. Tampilan produk yang sudah dipromosikan dan dijual pada e-commerce www.bumbuminangunieque.com

\section{KESIMPULAN DAN SARAN}

Kegiatan ini merupakan hasil dari pelaksanaan Program Iptek Berbasis Dosen dan Masyarakat tahun 2018 yang didanai oleh LPPM Universitas Andalas. Dari tanya jawab dan diskusi yang telah dilakukan di tahapan awal, diperoleh beberapa masalah yang dihadapi oleh usaha Kelompok Tani Mutiara Indah sebagai salah satu UKM unggulan yang ada di Kabupaten Tanah Datar dalam usaha bumbu masakan. Pada pertemuan 
berikutnya dilakukan pengenalan tentang apa itu $e$-commerce dan praktek $e$-commerce dengan memanfaatkan media sosial yang telah dimiliki oleh Kelompok Tani Mutiara Indah semisal facebook atau bbm untuk memperkenalkan kepada pelaku UKM ini tentang pemanfaatan e-commerce. Kegiatan ini dilakukan untuk membekali Kelompok Tani Mutiara Indah di Cubadak Limo Kaum Kab. Tanah Datar tentang aplikasi $e$ commerce sebagai media online untuk memperluas jangkauan promosi produk dan menumbuhkan jaringan usaha bumbu masakan Kelompok Tani Mutiara Indah di kabupaten Tanah Datar kepada konsumen atau masyarakat umum secara luas. Metode ini untuk sebagai salah satu solusi dari kendala yang dihadapi sebelumnya dan menjadi target dari kegiatan pelatihan yang dilakukan.

Dampak dan manfaat dari pelaksanaan Program Iptek Berbasis Dosen dan Masyarakat ini bagi Kelompok Tani Mutiara Indah di Cubadak Limo Kaum Kab. Tanah Datar adalah adanya sebuah aplikasi e-commerce berupa website yang dapat dikelola secara baik oleh Kelompok Tani Mutiara Indah di kabupaten Tanah Datar untuk mempromosikan produk bumbu masakan kepada konsumen atau masyarakat umum secara luas serta dapat diakses secara online dengan memanfaatkan fasilitas internet yang memadai.

\section{UCAPAN TERIMA KASIH}

Penulis mengucapkan terima kasih kepada LPPM Universitas Andalas sebagai sumber dana pelaksanaan kegiatan Program IptekS Berbasis Dosen dan Masyarakat (IbDM) Tahun 2018 bagi Kelompok Tani Mutiara Indah.

\section{DAFTAR PUSTAKA}

Dudung. 2015. Pengertian, model dan kunci sukses membangun e-commerce. Diakses melalui http://www.dosenpendidikan.com/pengertian-model-dan-kunci-sukses membangun-e-commerce/ tanggal 04 Juni 2016

Gupta, A. 2014. E-Commerce : Role of e-commerce in today's business. International journal of computing and corporate research. 4(1)

Indratji, R. E. 2002. Electronic Commerce: Strategi dan Konsep Bisnis di Dunia Maya. Aptikom

Khuzaeni. 2011. Karakteristik e-commerce. Diakses melalui https://uchewthirteen.wordpress.com/2011/03/28/karakteristik-e-commerce/ tanggal 04 Juni 2016

Kementerian Koperasi dan UKM. 2016. Momentum penting UKM tingkatkan bisnis ecommerce. Diakses dari http://www.depkop.go.id/content/ read/momentumpenting-ukm- tingkatkan-bisnis-e-commerce/ tanggal 1 Jni 2016 
Watson, Richard T., Pierre Berthon, Leyland F. Pitt, George M. Zinkhan. 2008. Electronic Commerce: The Strategic Perspective. Jacobs Foundation, Zurich, Switzerland 